\title{
ANALISIS VARIASI NILAI VELOCITY ENCODING (VENC) TERHADAP INFORMASI ANATOMI CITRA MAGNETIC RESONANCE VENOGRAPHY (MRV) BRAIN PADA MODALITAS MRI 3 TESLA
}

\section{ANALYSIS OF VELOCITY ENCODING (VENC) VARIATIONS TO ANATOMICAL INFORMATIONS OF BRAIN MAGNETIC RESONANCE VENOGRAPHY (MRV) ON 3 TESLA MRI DEVICES}

\author{
Sugiyanto $^{1)}$, Ardi Soesilo Wibowo ${ }^{2)}$, I Gusti Agung Brihaspaty Bhuana ${ }^{3)}$ \\ ${ }^{1,2,3)}$ Health Polytechnics of Semarang-Indonesia \\ e-mail: gieksugiyanto@yahoo.com
}

\begin{abstract}
Background: The imaging for vein vessels or Magnetic Resonance Venography (MRV) has own role and advantages on MRI examinations, specifically for evaluating intracranial blood vein circulation. MRV generally uses Phase Contrast (PC) method and PC-MRV imaging, there is an important parameter to be considered, its velocity encoding or VENC. VENC is selected before the examination and has to be adjusted the anticipated blood flow velocity in the examined organs. The right selection of VENC will result in optimum intracranial vessels images and accurate diagnose. The aim of this study is to figure out if there is significant effect of VENC on anatomical information of brain MRV and to find out which VENC the best intracranial veins demonstrates.

Methods: This research was a quantitative study with quasi - experimental approach. Data were obtained from five healthy volunteers who were scanned by using a 3 Tesla MRI device in Radiology Department Siloam Lippo Village Hospitals. Each volunteer was scanned with five VENC variations: $10 \mathrm{~cm} / \mathrm{s}, 15 \mathrm{~cm} / \mathrm{s}, 20 \mathrm{~cm} / \mathrm{s}, 25 \mathrm{~cm} / \mathrm{s}$, and $30 \mathrm{~cm} / \mathrm{s}$. The MRV images were assessed by two radiologist as the respondent. The Data were analyzed by simple linear regression test and Friedman test.

Result: The results showed that there was significant effect of VENC on anatomical information of brain MRV, with significant value below 0,001 ( $\mathrm{p}$ value $<0,05$ ). Mean rank on Friedman test showed that the best VENC to demonstrate intracranial veins was $25 \mathrm{~cm} / \mathrm{s}$.

Conclution: There was a significant effect of VENC on anatomical information of brain MRV with the VENC of $25 \mathrm{~cm} / \mathrm{s}$ gave the best image of intracranial veins in general.
\end{abstract}

Keywords: Phase contrast, Magnetic Resonance Venography (MRV), velocity encoding (VENC)

\section{PENDAHULUAN}

Evaluasi pembuluh darah pada MRI menggunakan metode tersendiri, karena tidak seperti jaringan lain, pembuluh darah mengandung darah yang terus bergerak sehingga memerlukan pendekatan tertentu agar pembuluh darah dapat tervisualiasi dengan baik. Istilah "MRA" atau Magnetic Resonance Angiography umumnya digunakan pada semua pemeriksaan MRI yang didesain untuk membedakan spin-spin yang bergerak mengalir (dalam hal ini spin pada darah) dan spin-spin yang diam (Lee, 2001). Meskipun demikian, istilah MRA lebih tepat digunakan untuk evaluasi pembuluh arteri menggunakan MRI, sedangkan pemeriksaan MRI untuk mengevaluasi pembuluh darah vena digunakan istilah "MRV", atau Magnetic Resonance Venography.

Menurut Lee (2011), secara umum, baik untuk MRA dan MRV, terdapat dua pendekatan utama untuk menghasilkan citra pembuluh darah yang sudah diterima secara luas, yaitu menggunakan pendekatan time-of-flight (TOF) dan pendekatan phase contrast (PC). Pendekatan TOF bergantung pada mekanisme kontras T1, sedangkan pendekatan PC menekankan pada perbedaan kontras jaringan T2. Terdapat variasi untuk kedua pendekatan tadi, yaitu citra dibuat secara dua dimensi (2D) dan tiga dimensi (3D). Selain dua pendekatan tadi, metode yang bisa digunakan adalah contrastenhanced (CE) MR. Namun metode ini lebih jarang digunakan karena risiko yang dapat ditimbulkan oleh media kontras.

Pendekatan PC mendapatkan kontras antara jaringan diam dengan darah yang mengalir dengan cara memanipulasi fase magnetisasi. Fase magnetisasi spin-spin dari jaringan stasioner adalah nol (zero) sedangkan spin-spin dari darah yang mengalir adalah tidak nol (non-zero). Fase, atau phase, adalah ukuran seberapa jauh presesi magnetisasi dari waktu proton mulai berubah ke bidang transversal sampai waktu sinyalnya terdeteksi. Gradien bipolar dengan besaran sama dan arah berlawanan digunakan untuk menghilangkan sinyal dari jaringan stasioner. Sebagai tambahan, metode PC sensitif terhadap kecepatan aliran darah, karena hal tersebut metode PC dianggap efektif untuk MRV karena aliran darah pada vena intrakranial cenderung lambat dibandingkan pada arteri. Pada pemeriksaan PC-MRV radiografer dapat memilih nilai aliran darah pada komputer. Nilai kecepatan yang dapat dipilih tersebut lazim disebut sebagai faktor Velocity Encoding (VENC). Pada pemeriksaan vena intrakranial, menurut Lee (2001), kecepatan aliran darah yang umum dijadikan patokan untuk pemilihan VENC adalah pada sinus dural dengan rentang kecepatan $15 \mathrm{~cm} / \mathrm{s}$ sampai $20 \mathrm{~cm} / \mathrm{s}$.

Pemeriksaan MRV umumnya dapat dilakukan pada modalitas MRI dengan kekuatan medan mulai dari 1,5 Tesla, dengan citra yang kualitasnya sudah memadai untuk evaluasi 
drainase vena. MRI dengan kekuatan 1,5T merupakan modalitas yang digunakan pada sebagian besar instalasi radiologi, namun saat ini mulai banyak yang beralih ke modalitas 3T. Pada umumnya, modalitas $3 \mathrm{~T}$ memiliki keunggulan pada waktu pemeriksaan yang lebih cepat dengan kualitas citra yang lebih baik. Citra akhir yang dihasilkan baik pada arteri dan vena, selain dipengaruhi oleh metode pendekatan yang digunakan juga dipengaruhi oleh kekuatan medan magnet modalitas MRI yang digunakan. Secara teori, dibandingkan sistem 1,5T, sistem 3T memiliki keunggulan pada signal to noise ratio (SNR) dan resolusi spasial, namun sistem 3T memiliki kelemahan pada efek kerentanan/susceptibility yang juga lebih tinggi. Sehingga ada beberapa hal yang harus dipertimbangkan dalam melakukan pencitraan pembuluh pada kedua sistem MR.

Tujuan dari penelitian ini adalah untuk mengetahui pengaruh variasi nilai VENC terhadap informasi citra PCMRV brain khususnya pada modalitas MRI 3T.

\section{METODE}

Jenis penelitian pada karya tulis ilmiah ini adalah penelitian kuantitatif dengan pendekatan eksperimen semu (quasi-eksperimen) yang bertujuan untuk mengetahui pengaruh variasi nilai VENC pada informasi anatomi citra MRV menggunakan modalitas MRI 3T.

Sampel yang digunakan adalah lima orang volunteer sehat di Instalasi Radiologi Siloam Hospitals Lippo Karawaci. Populasi penelitian adalah seluruh pemeriksaan PC-MRV selama bulan Desember 2016 di Instalasi Radiologi Siloam Hospitals Lippo Karawaci. Responden atau Reviewer yang memberikan penilaian adalah 1 (satu) orang dokter spesialis radiologi dan 1 orang dokter spesialis radiologi sebagai parameter konsistensi subjektifitas Reviewer.

Prosedur dalam penelitian ini adalah voluntir diberikan informed consent tentang maksud dan tujuan penelitian, serta diberi penjelasan tentang prosedur pemeriksaan, serta diyakinkan bahwa penelitian ini tidak berbahaya bagi mereka. Pengaturan nilai VENC yang akan digunakan. Dilakukan pemeriksaan PC MRV. Setiap voluntir dilakukan scanning dengan lima variasi nilai VENC, yaitu $10 \mathrm{~cm} / \mathrm{s}, 15 \mathrm{~cm} / \mathrm{s}$, $20 \mathrm{~cm} / \mathrm{s}, 25 \mathrm{~cm} / \mathrm{s}$ dan $30 \mathrm{~cm} / \mathrm{s}$. Citra hasil penelitian tersebut disimpan dalam CD dengan format DICOM tanpa ada keterangan identitas apapun, hanya diberikan kode serial voluntir dan variasi VENC yang digunakan. Dua orang dokter spesialis radiologi yang berpengalaman di bidang MRI 3 Tesla dimohon untuk mencermati citra dari masing-masing gambar.Penilaian dokter spesialis radiologi dilakukan dengan memberikan tanda check $(\sqrt{ })$ pada kuesioner yang telah disediakan. Pertanyaan tentang kejelasan citra diberikan nilai 1 dengan arti tidak jelas, bila citra yang dinilai tidak terlihat. Nilai 2 dengan arti kurang jelas, bila citra yang dinilai terlihat, namun tidak tegas atau batas tidak jelas. Nilai 3 dengan arti jelas, bila citra yang dinilai terlihat dengan batas yang tegas.

Data yang diperoleh adalah skor penilaian citra oleh radiolog yang merupakan data berjenis ordinal, data ini dikonversi menjadi data interval menggunakan metode suksesif interval (methode of succesive interval/MSI) yang kemudian diolah menggunakan aplikasi statistik pada komputer, yaitu aplikasi Statistical Package for Social Sciences (SPSS) versi 16.00. Uji statistika selanjutnya menggunakan metode statistika regresi linier sederhana untuk menilai ada tidaknya pengaruh yang signifikan pada variasi nilai VENC terhadap informasi anatomis pada MRV brain dan uji Friedman untuk mengetahui nilai VENC mana yang paling baik menampakkan formasi pembuluh darah vena intracranial

\section{HASIL}

Penelitian dilakukan terhadap lima orang berjenis kelamin laki - laki dan perempuan, rentang usia 20 - 23 tahun.

Tabel 1: Deskripsi sampel berdasarkan jenis kelamin

\begin{tabular}{ccc}
\hline Jenis Kelamin & Jumlah & Persentase \\
\hline Laki-laki & 3 & $60 \%$ \\
Perempuan & 2 & $40 \%$ \\
\hline Total & 5 & $100 \%$ \\
\hline
\end{tabular}

Tabel 2: Deskripsi sampel berdasarkan usia

\begin{tabular}{ccc}
\hline Usia (tahun) & Jumlah & Persentase \\
\hline 22 & 1 & $20 \%$ \\
23 & 3 & $60 \%$ \\
24 & 1 & $20 \%$ \\
\hline Total & 5 & $100 \%$ \\
\hline
\end{tabular}

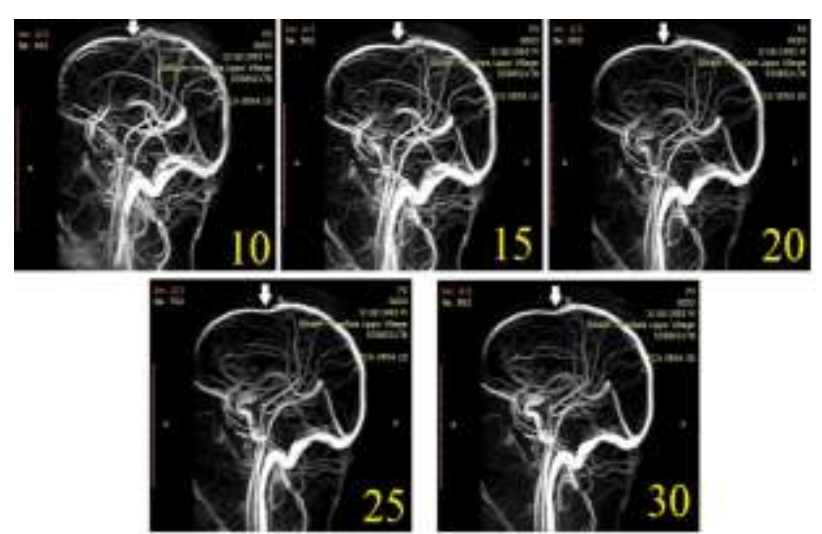

Gambar 1. Sampel hasil penggunaan variasi VENC $10 \mathrm{~cm} / \mathrm{s}, 15 \mathrm{~cm} / \mathrm{s}$, $20 \mathrm{~cm} / \mathrm{s}, 25 \mathrm{~cm} / \mathrm{s}$, dan $30 \mathrm{~cm} / \mathrm{s}$ pada citra MRV brain. Signal void dapat terjadi karena penggunaan VENC yang tidak tepat. Dapat dilihat pada Sinus Sagitalis Superior signal void pada variasi normal (tanpa panah putih) tampak lebih parah pada citra dengan VENC 10, namun berangsur membaik pada VENC yang lebih tinggi.

Pada tiap volunteer dilakukan pemeriksaan MRV dengan sekuens PC menggunakan variasi VENC yaitu $10 \mathrm{~cm} / \mathrm{s}, 15$ $\mathrm{cm} / \mathrm{s}, 20 \mathrm{~cm} / \mathrm{s}, 25 \mathrm{~cm} / \mathrm{s}$, dan $30 \mathrm{~cm} / \mathrm{s}$. Hasil penelitian ini berjumlah 25 seri citra, di mana tiap seri merupakan hasil penggunaan satu variasi VENC. Satu seri hasil pemeriksaan terdiri dari 12 citra MRV yang menampakkan bagian anatomi vena serebral, yaitu Sinus Sagitalis Superior, Sinus Sagitalis Inferior, Straight Sinus, Sinus Transversal, Sinus Serebral Internal, Sinus Sigmoid, Vena Jugularis, Vena Galen, dan Vena Trolard dari beberapa sudut pandang untuk memudahkan evaluasi masing-masing bagian vena tersebut. 
Setelah hasil citra PC-MRV brain dievaluasi dan diberi skor oleh responden, pengujian statistika pertama yang dilakukan adalah untuk mengetahui pengaruh variasi VENC terhadap informasi anatomi pada MRV brain, dilakukan pengujian Kappa untuk mengetahui tingkat kesepakatan atau kesamaan persepsi antar dua responden dalam pemberian skor penilaian citra. Hasil pengujian Kappa terhadap dua responden adalah sebagai berikut:

Tabel 3. Hasil uji kappa pada dua responden

\begin{tabular}{ccc}
\hline $\begin{array}{c}\text { Variasi } \\
\text { VENC }\end{array}$ & $\begin{array}{c}\text { Kappa } \\
\text { Measurement }\end{array}$ & $\begin{array}{c}\text { Approx. } \\
\text { Sig. }\end{array}$ \\
\hline 10 & 0,677 & $<0,001$ \\
15 & 0,667 & $<0,001$ \\
20 & 0,684 & $<0,001$ \\
25 & 0,709 & $<0,001$ \\
30 & 0,640 & $<0,001$ \\
\hline
\end{tabular}

Pada tabel 3 dapat dilihat bahwa nilai uji Kappa pada semua variabel adalah di atas 0,6 dan berdasar pada interpretasi uji Kappa oleh Viera (2005), nilai ini ada pada kategori kesepakatan kuat.

Uji statistika selanjutnya adalah uji regresi linier sederhana untuk mengetahui adanya pengaruh signifikan antara variasi nilai VENC terhadap informasi anatomi citra MRV brain. Hasil uji Regresi dilakukan pada citra vena intrakranial secara keseluruhan serta citra per-bagian anatomi vena intrakranial.

Tabel 4: Hasil uji regresi pemeriksaan MRV brain dengan variasi VENC terhadap informasi anatomi vena serebral secara keseluruhan

\begin{tabular}{ccc}
\hline $\mathrm{R}$ & $\mathrm{R}$ square & Sig. \\
\hline 0,726 & 0,527 & $<0,001$ \\
\hline
\end{tabular}

Tabel 5: Hasil uji regresi pada tiap bagian vena serebral

\begin{tabular}{lccr}
\hline Bagian Anatomi & $\mathrm{R}$ & $\begin{array}{c}\mathrm{R} \\
\text { Square }\end{array}$ & \multicolumn{1}{c}{ Sig. } \\
\hline Sinus Sagitalis Superior & 0,734 & 0,552 & $<0,001$ \\
Sinus Sagitalis Inferior & 0,495 & 0,246 & 0,012 \\
Straight Sinus & 0,734 & 0,615 & $<0,001$ \\
Sinus Transversal & 0,832 & 0,692 & $<0,001$ \\
Sinus Serebral Internal & 0,662 & 0,438 & $<0,001$ \\
Sinus Sigmoid & 0,555 & 0,308 & $<0,001$ \\
Vena Jugularis & 0,766 & 0,587 & $<0,001$ \\
Vena Galen & 0,482 & 0,233 & 0,015 \\
Vena Trolard & 0,586 & 0,343 & 0,002 \\
\hline
\end{tabular}

Pada kedua tabel (tabel 4 dan 5) dapat dilihat bahwa nilai signifikansi pada uji regresi adalah $<0,05 \quad(\mathrm{p}<0,05)$ yang berarti ada pengaruh signifikan antara nilai VENC terhadap informasi anatomi citra MRV brain secara keseluruhan dan perbagian anatomi. Selanjutnya yang dilihat adalah nilai $\mathrm{R}$, nilai $\mathrm{R}$ menunjukkan kekuatan hubungan antara VENC dan informasi anatomi. Pada regresi secara keseluruhan didapatkan nilai R 0,726. Sesuai dengan pedoman oleh Sugiyono (2007), nilai ini ada pada kategori pengaruh kuat. hal ini menandakan ada hubungan signifikan yang kuat antara variasi VENC terhadap informasi anatomi PC-MRV brain, khususnya pada anatomi secara keseluruhan. Kemudian yang juga harus diperhatikan adalah $\mathrm{R}$ square, yang menunjukkan persentase pengaruh VENC terhadap informasi anatomi. R square yang dihasilkan adalah 0,527 yang berarti pengaruh VENC terhadap informasi citra secara keseluruhan adalah $52,7 \%$ sedangkan $47,7 \%$ dipengaruhi oleh faktor atau parameter lain.

Pada uji regresi per-bagian anatomi didapatkan hasil $\mathrm{R}$ pada kategori kuat di bagian sinus sagitalis superior, straight sinus, sinus transversal, sinus serebral internal, dan vena jugular, sedangkan sisanya ada pada kategori pengaruh sedang. Nilai $\mathrm{R}$ terkecil ada di bagian Vena Galen yaitu sebesar 0,482. $\mathrm{R}$ square yang menunjukkan persentase pengaruh di atas 50\% ada di bagian Sinus Sagitalis Superior, Straight Sinus, Sinus Transversal, Dan Vena Jugular dengan persentase terbesar ada di bagian sinus transversal $(69,2 \%)$, sedangkan $\mathrm{R}$ square yang menunjukkan persentase pengaruh di bawah $50 \%$ ada di bagian Sinus Sagittal Inferior, Sinus Serebral Internal, Sinus Sigmoid, Vena Galen, dan Vena Trolard dengan persentase pengaruh VENC terkecil ada di bagian Vena Galen $(23,3 \%)$.

Pengujian statistika selanjutnya adalah uji Friedman untuk mengetahui nilai VENC mana yang paling baik dalam menampakkan citra vena intrakranial. Pengujian juga dilakukan pada anatomi secara keseluruhan dan per-bagian anatomi. Pada pengujian ini yang dilihat adalah mean ranknya.

Tabel 6: : Hasil uji Friedman terhadap masing-masing variabel pada anatomi keseluruhan

\begin{tabular}{|c|c|c|c|c|c|}
\hline \multicolumn{2}{|l|}{$\begin{array}{l}\text { Variasi nilai } \\
\text { VENC }\end{array}$} & \multicolumn{2}{|c|}{ Mean Rank } & & $\begin{array}{l}\text { Asymp. } \\
\text { Sig. }\end{array}$ \\
\hline 10 & & \multicolumn{2}{|c|}{1,76} & & \multirow{5}{*}{$<0,001$} \\
\hline 15 & & \multicolumn{2}{|c|}{2,37} & & \\
\hline 20 & & \multicolumn{2}{|c|}{3,24} & & \\
\hline 25 & & \multicolumn{2}{|c|}{4,06} & & \\
\hline 30 & & \multicolumn{2}{|c|}{3,68} & & \\
\hline \multirow{2}{*}{$\begin{array}{l}\text { Variasi } \\
\text { VENC }\end{array}$} & \multicolumn{5}{|c|}{ Mean Rank } \\
\hline & SSS & SSI & SS & ST & SSrInt \\
\hline 10 & 1,30 & 1,90 & 1,30 & 1,20 & 1,50 \\
\hline 15 & 2,50 & 1,90 & 2,10 & 2,20 & 3,00 \\
\hline 20 & 3,00 & 3,20 & 3,40 & 3,00 & 3,40 \\
\hline 25 & 4,30 & 4,30 & 4,30 & 4,50 & 3,70 \\
\hline 30 & 3,90 & 3,70 & 3,90 & 4,10 & 3,40 \\
\hline \multirow{2}{*}{\multicolumn{2}{|c|}{ Variasi VENC }} & \multicolumn{4}{|c|}{ Mean Rank } \\
\hline & & $\mathrm{SSg}$ & $\mathrm{VJ}$ & VG & $\mathrm{VT}$ \\
\hline \multicolumn{2}{|c|}{10} & 1,80 & 1,30 & 2,30 & 2,00 \\
\hline \multicolumn{2}{|l|}{15} & 2,20 & 1,80 & 2,00 & 2,40 \\
\hline
\end{tabular}




\begin{tabular}{lllll}
20 & 3,10 & 3,90 & 2,70 & 2,40 \\
25 & 4,30 & 4,20 & 4,40 & 4,40 \\
30 & 3,60 & 3,80 & 3,60 & 3,80 \\
\hline
\end{tabular}

Tabel 6 dan 7 menunjukkan mean rank dari hasil uji Friedman pada anatomi vena intrakranial secara keseluruhan dan per-bagian vena intrakranial yang dinilai responden. Nilai VENC dengan Mean rank tertinggi berarti menampakkan citra paling baik. Dari kedua tabel tersebut dapat dilihat bahwa VENC 25 memiliki mean rank tertinggi baik pada uji Friedman pada anatomi secara keseluruhan maupun perbagian anatomi vena intrakranial.

\section{DISKUSI}

Pengujian statistika yang dilakukan adalah uji regresi linier dan dianjutkan dengan uji Friedman. Hasil uji regresi linier pada citra keseluruhan menunjukkan nilai signifikansi $<0,001$ ( $p$ value $<0,05)$, yang berarti terdapat pengaruh signifikan VENC terhadap informasi citra vena intrakranial secara keseluruhan. Kemudian dengan uji statistika Friedman didapatkan nilai VENC yang paling baik untuk mencitrakan pembuluh vena intrakranial secara keseluruhan adalah 25 $\mathrm{cm} / \mathrm{s}$.

VENC yang dipilih harus berdasarkan kecepatan pembuluh darah pada organ yang diperiksa, untuk kecepatan darah pada vena intrakranial secara teori menurut Woodward (2001) adalah $15 \mathrm{~cm} / \mathrm{s}-20 \mathrm{~cm} / \mathrm{s}$, sehingga sebaiknya VENC yang dipilih adalah pada rentang nilai tersebut. Namun jika dilihat dari hasil uji statistika ini, VENC yang paling baik menampakkan semua bagian vena intrakranial adalah 25 $\mathrm{cm} / \mathrm{s}$. Nilai tersebut juga digunakan sebagai parameter tetap pada pemeriksaan PC-MRV brain. Walaupun terkesan terpaut jauh dari rentang yang disarankan, nilai ini sebetulnya masih lazim digunakan karena menurut Woodward sendiri, VENC memang sebaiknya diatur sedikit lebih tinggi dari kecepatan aliran darah yang diantisipasi untuk menghindari signal void sehingga didapatkan citra pembuluh darah yang yang optimum dan terhindar dari misinterpretasi.

Untuk pengujian statistika pada masing-masing organ, semuanya menunjukkan adanya pengaruh signifikan antara penggunaan VENC terhadap informasi anatomis, hanya saja berdasar pada nilai R square terlihat seperti VENC memiliki persentase pengaruh yang sangat kecil pada beberapa organ, yaitu Sinus Sagitalis Inferior, Vena Galen, dan Vena Trolard ( $\mathrm{R}$ square masing-masing adalah 0,246, 0,233, dan 0,343). Hal ini bisa saja terjadi karena metode penghitungan regresi linier idealnya digunakan untuk data yang menunjukka peningkatkan atau penurunan linier pada tiap perubahan variabel, sedangkan penilaian responden pada organ-organ ini konstan pada tiap variasi VENC yang digunakan dan beberapa cenderung berkurang di VENC paling tinggi, karenanya hasil keluaran nilai $\mathrm{R}$ square tidak begitu baik. Hal tadi dapat juga berarti berapapun penggunaan VENC (sepanjang pada rentang yang digunakan pada penelitian ini), tidak terlalu berpengaruh pada kejelasan citra organ-organ yang diuji. Uji Friedman juga dilakukan untuk melihat variasi VENC yang paling baik untuk menampakkan masing-masing organ dan mean rank semua organ menunjukkan nilai tertinggi pada VENC $25 \mathrm{~cm} / \mathrm{s}$. Secara lebih detail, walaupun terlihat jelas mean rank tertinggi pada $25 \mathrm{~cm} / \mathrm{s}$, namun mean rank pada masing-masing organ tidak terlampau jauh pada VENC $20 \mathrm{~cm} / \mathrm{s}, 25 \mathrm{~cm} / \mathrm{s}$, dan 30 $\mathrm{cm} / \mathrm{s}$. Hal ini menunjukkan bahwa perbedaan pada citra antara tiga nilai VENC tersebut tidak terlalu besar.

Secara umum, VENC merupakan parameter yang penting pada pencitraan MRV, khususnya vena intrakranial, dengan metode PC, namun tidak kalah penting untuk diperhatikan adalah pengaturan repetition time (TR) dan echo time (TE). Walaupun VENC merupakan faktor yang penting dalam mencitrakan pembuluh darah pada metode PC, TR dan TE tetap memiliki pengaruh besar. Hal ini dapat dilihat dari hasil pengujian statistika regresi linier, di mana secara keseluruhan VENC memiliki pengaruh terhadap informasi citra sebesar $52,7 \%$, yang juga berarti $47,3 \%$ dipengaruhi oleh faktor lain. Faktor lain tentu saja mencakup TR dan TE yang juga merupakan faktor utama pada seluruh pemeriksaan MRI. Tidak seperti metode TOF yang bergantung pada pengaturan TR, pada metode PC sendiri yang lebih diutamakan adalah pengaturan TE.

Menurut Woodward (2001), nilai minimum TE pada metode PC dibuat lebih besar daripada nilai minimum TE pada metode TOF. Sebagai konsekuensinya, nilai TE yang besar tadi dapat menyebabkan signal loss berlebih pada pembuluh darah, hal ini khususnya berpengaruh pada pembuluh darah dengan stenosis di mana signal loss dapat menyebabkan stenosis terlihat sangat parah dari kondisi sebenarnya. Berdasar hal ini, maka TE yang ada di protokol pemeriksaan PC MRV di lokasi penelitian penulis dibuat seminimal mungkin untuk mengurangi efek signal loss dengan kompensasi peningkatan VENC agar pembuluh darah tetap dapat dicitrakan secara optimal. Sehingga VENC yang digunakan lebih tinggi daripada VENC di tempat lain dengan menggunakan alat MRI sejenis.

Apabila dibandingkan dengan penelitian sejenis yang telah dilakukan, pada penelitian oleh Zita Hadiah Pratami (2016), secara keseluruhan informasi anatomi MRV brain paling baik ditampakkan dengan VENC $20 \mathrm{~cm} / \mathrm{s}$, namun pada penelitian ini tidak dilakukan pengujian pada VENC $25 \mathrm{~cm} / \mathrm{s}$ sehingga citra yang dihasilkan pada VENC ini tidak diketahui hasilnya. Kemudian pada penelitian oleh Francesco Fera (2004) mengenai perbandingan metode MRV pada pasien dengan hipertensi intrakranial idiopatik (idiopathic intracranial hypertension/IIH), di mana pada metode PC digunakan VENC $15 \mathrm{~cm} / \mathrm{s}$ dan $40 \mathrm{~cm} / \mathrm{s}$. Hasil yang didapatkan adalah VENC $15 \mathrm{~cm} / \mathrm{s}$ dan $40 \mathrm{~cm} / \mathrm{s}$ dapat menampakkan vena intrakranial dengan baik, namun dalam menampakkan IIH VENC $15 \mathrm{~cm} / \mathrm{s}$ lebih baik daripada $40 \mathrm{~cm} / \mathrm{s}$. Hal ini terjadi karena VENC $15 \mathrm{~cm} / \mathrm{s}$ dapat menggambarkan gangguan pada aliran vena lebih baik daripada VENC $40 \mathrm{~cm} / \mathrm{s}$. Penggunaan nilai VENC yang bervariasi pada aplikasi pemeriksaan PCMRV dapat terjadi karena perbedaan kuat magnet pada alat MRI yang digunakan pada tiap penelitian, di mana kedua penelitian ini menggunakan MRI dengan kekuatan magnet 1,5 Tesla, selain itu vendor modalitas MRI yang digunakan juga 
berbeda-beda yang berarti pengaturan parameter-parameter seperti TE, TR, flip angle, dan banyak parameter default lainnya berbeda. Contohnya penelitian Zita menggunakan TE $5,2 \mathrm{~ms}$ dengan TR $10 \mathrm{~ms}$ dan flip angle $15^{\circ}$, sedangkan penelitian Franseco Fera menggunakan TE 7,2 ms dengan TR $26 \mathrm{~ms}$ dan flip angle $20^{\circ}$. Perbedaan-perbedaan parameter tersebut menyebabkan citra PC-MRV brain yang dihasilkan menjadi berbeda juga.

\section{SIMPULAN}

Ada pengaruh secara signifikan antara variasi VENC terhadap informasi anatomi citra pada pemeriksaan PC-MRV brain dengan $p$ value $<0,05$. Sesuai dengan hasil uji statistika, VENC memiliki pengaruh sebesar 52,7\% terhadap informasi anatomi vena serebral secara keseluruhan. Jika dilihat perbagian, pengaruh VENC terbesar ada pada bagian Sinus Transversal yaitu $69,2 \%$ dan pengaruh terendah ada pada Vena Galen dengan persentase 23,3\%. Perbedaan pengaruh pada masing-masing bagian vena serebral bukan hanya diakibatkan oleh VENC saja, tetapi juga parameter lain terutama TE. Nilai VENC yang paling baik menampakkan vena intrakranial secara keseluruhan dan per-bagian anatomi vena intrakranial adalah $25 \mathrm{~cm} / \mathrm{s}$.

Direkomendasikan penggunaan nilai VENC $25 \mathrm{~cm} / \mathrm{s}$ dalam melakukan pemeriksaan PC-MRV brain. Harus diperhatikan juga nilai TE yang digunakan untuk mendapatkan citra vena intrakranial yang lebih optimal.

Disarankan untuk dilakukan penelitian lanju tan untuk menguji pengaruh VENC pada pemeriksaan PC - MRV brain pada pasien yang mengalami stenosis vena intrakranial.

\section{DAFTAR PUSTAKA}

Atlas, Scott W. 2009. Magnetic Resonance Imaging of the Brain and Spi ne Volume 1: Fourth Edition. Lippincott Williams and Wilkins, a Wolters Kluwer Business : Amerika Serikat.

Ayanzen, R.H., et.al. 2000. Cerebral MR Venography: Normal Anatomy and Potential Diagnostic Pitfalls. American Journal Of Neuroradiology. Amerika Serikat.

Brown, Mark A., Semelka, Richard C. 2010. MRI: Basic Principles and Applications: Fourth Edition. Wiley-Blackwell : Amerika Serikat.

Erkonen, William E.; Smith, Wilbur E. 2010. Radiology 101, the Basics and Fundamentals of Imaging: Third Edition. Lippincott Williams and Wilkins : Amerika Serikat.

Fera, Francesco, et al. 2005. Comparison of Different MR Venography Techniques for Detecting Transverse Sinus Stenosis in Idiopathic Intracranial Hypertension. Institute of Neurology University Magna Graecia Catanzaro : Italia.

Gaillard, Frak, Prof A. 2008. 1,5T vs 3T. Radiopaedia : Amerika Serikat http://radiopaedia.org/articles/15t-vs-3t, diakses pada tanggal 27 Agustus 2016.

Glockner, James F., Lee, Christine U. 2010. Magnetic Resonance Venography. Amerika Serikat. http://www.medscape.com/ viewarticle /724424, diakses pada tanggal 1 Agustus 2016.

Korosec, Frank R. 2011. Basic Principles of Phase-contrast, Time-of-flight, and Contrast-enhanced MR Angiography. Springer : Amerika Serikat.

Paoletti, M.; Germani, G., De Icco, R., Asteggiano, C., Zamboni, P. Bastianello, S. 2016. Intra- and Extracranial MR Venography: Technical Notes, Clinical Application, and Imaging Development Behavioural Neurology - Hindawy Publishing Corporation : Italy.

Sandrick, Kendra. 2001. 3-Tesla MRI Bests 1.5-Tesla In Body And Brain. CMP Media, LLC a United Business Media Company : Amerika Serikat.
Schaller, B. 2004. Physiology of Cerebral Venous Blood Flow: From Experimental Data in Animals to Normal Function In Humans. Elsevier : Jerman.

Simons, Barbara, Nijeholt, Lycklama A; Smithuis, Robin. 2010. Cerebral Venous Thrombosis, Belanda, The Radiology Assistant: http:// www.radiologyassistant.nl/en/p4befacb3e4691/cerebral-venousthrombosis.html, diakses pada tanggal 18 Agustus 2016.

Viera, A. J., Garrett, J. M. 2005. Understanding Interobserver Agreement: The Kappa Statistic. Family Medicine - Research Series : North Carolina - USA.

Vummidi, Dharshan. 2011. MR Angiography: Techniques. Department of Radiology University of Michigan :, Amerika Serikat.

Westbrook, Catherine; Kaut, Carolyn; Talbot, John, 2011, MRI in Practice: Fourth Edition. Blackwell Publishing Ltd. : UK

Woodward, Peggy. 2001. MRI for Technologists: Second Edition. McGraw Hill Professional : , Amerika Serikat. 